\title{
Urotensin II promotes aldosterone expression in rat aortic adventitial fibroblasts
}

\author{
JUN LI $^{1,2}$, YONG-GANG ZHANG ${ }^{3}$, LI-MIN LUO ${ }^{4}$, XIAO DONG $^{2}$, WEN-HUI DING ${ }^{1}$ and SHU-YI DANG ${ }^{2}$ \\ ${ }^{1}$ Division of Cardiology, Department of Internal Medicine, Peking University First Hospital, Beijing 100034; ${ }^{2}$ Division of \\ Cardiology, Department of Internal Medicine, Taihe Hospital, Hubei University of Medicine, Shiyan, Hubei 442000; \\ ${ }^{3}$ Department of Cardiovascular Diseases, Second Affiliated Hospital, Shantou University Medical College, \\ Shantou, Guangdong 515041; ${ }^{4}$ Department of Dermatology, Dongfeng General Hospital, \\ Hubei University of Medicine, Shiyan, Hubei 442000, P.R. China
}

Received January 3, 2017; Accepted November 24, 2017

DOI: $10.3892 / \mathrm{mmr} .2017 .8233$

\begin{abstract}
Urotensin II (UII) contributes to cardiovascular diseases by activating vasoactive peptides. The present study aimed to determine the effect of UII on aldosterone (ALD) and its receptor in cultured adventitial fibroblasts (AFs) and the tunica adventitia of rat vessels to explore the possible mechanisms underlying vascular remodeling. Expression levels of aldosterone and its receptor on tunica adventitia were determined using immunohistochemistry. Growth-arrested AFs and tunica adventitia from rat vessels were incubated with UII and inhibitors of various signal transduction pathways. ALD receptor (ALD-R) mRNA expression levels and ALD protein exoression levels were determined by reverse transcription-quantitative polymerase chain reaction and ELISA, respectively. Aldosterone and its receptors were expressed on tunica adventitia. UII promoted ALD protein secretion from cells in a dose- and time-dependent manner. ALD-R mRNA expression in cells was also dysregulated. Furthermore, the effects of UII were substantially inhibited by treatment with the inhibitors PD98059, Y-27632, H-7, CSA and
\end{abstract}

Correspondence to: Professor Wen-Hui Ding, Division of Cardiology, Department of Internal Medicine, Peking University First Hospital, 8 Xishikudajie, Beijing 100034, P.R. China

E-mail: dwh_rd@126.com

Professor Shu-Yi Dang, Division of Cardiology, Department of Internal Medicine, Taihe Hospital, Hubei University of Medicine, 32 South People's Road, Shiyan, Hubei 442000, P.R. China

E-mail: hbysthdsy@126.com

Abbreviations: ALD, aldosterone; ALD-R, aldosterone receptor; AFs, adventitial fibroblasts; ET-1, endothelin-1; FBS, fetal bovine serum; IL-6, interleukin-6; MRs, mineralocorticoid receptors; MCP-1, monocyte chemoattractant protein $1 ; \alpha$-SMA, $\alpha$-smooth muscle actin; UII, urotensin II; VSMCs, vascular smooth muscle cells

Key words: urotensin II, aldosterone, signal transduction, adventitial fibroblasts, vessels nicardipine. These results were further verified in the tunica adventitia of rat vessels. The present findings indicated that UII stimulated ALD protein secretion and ALD-R mRNA expression in AFs and in the tunica adventitia of rat vessels; moreover, this effect may be mediated by signal transduction pathways involving MAPK, Rho, $\mathrm{PKC}$, calcineurin and $\mathrm{Ca}^{2+}$. UII may also contribute to vascular remodeling by stimulating the production of ALD and its receptor.

\section{Introduction}

Urotensin II (UII) is a highly potent vasoconstrictor, with stronger vasoconstrictive effects than those of endothelin-1 (ET-1). GPR14, also known as the urotensin receptor (UT), is the specific receptor of UII. Both UII and its receptor are primarily expressed in cardiovascular tissues, such as cardiomyocytes, vascular smooth muscle cells (VSMCs) and endothelial cells (1). In addition to its vasoconstrictor activity, UII exerts various effects on cell proliferation, migration, hypertrophy, apoptosis, fibrosis, immunity and inflammatory responses in a wide variety of cell types in the cardiovascular system (2-5). UII also inhibits insulin release, modulates catecholamine release, and helps regulate food intake and the sleep cycle (2).

UII and UT were upregulated in cardiovascular diseases and metabolic syndrome (6), and UII receptor antagonism was shown to significantly attenuate diabetes-associated atherosclerosis in diabetic apolipoprotein E knockout mice (7). UII plays a pivotal role in the development of diseases, such as cardiovascular disease and diabetes mellitus (1). Furthermore, increased expression of UII was related to subendothelial inflammation in the pathogenesis of coronary atherosclerosis (8). In human umbilical vein endothelial cells and human monocytes, UII induced IL-1 $\beta$ and IL-6 expression (9).

Vascular inflammation plays critical roles in the development of various cardiovascular disease, such as hypertension, heart failure, vascular restenosis and atherosclerosis (10). Previously, this inflammation was considered an 'inside-out' response involving monocyte adhesion to the intima of blood vessels, as described in the oxidative lipid hypothesis (11). However, increasing evidence supports a new paradigm, 
which can be described as the 'outside-in' hypothesis, in which vascular inflammation initiates in the adventitia and progresses toward the intima (12).

Following paracrine/autocrine stimulation, AFs are activated, and acquire a myofibroblast phenotype, characterized by increased expression of the cytoskeletal protein $\alpha$-smooth muscle actin ( $\alpha$-SMA) (13-16). Then, AFs synthesize a panel of cytokines and other molecules, such as interleukin-6 (IL-6) and monocyte chemoattractant protein-1 (MCP-1), both of which contribute to proinflammatory activation and vascular remodeling $(10,12)$.

Aldosterone (ALD), the key hormone in the mineralocorticoid pathway, binds to mineralocorticoid receptors (MRs) in the kidney. By affecting cell adhesion and cytokine expression, MRs play an important role in salt and water homeostasis, blood pressure regulation, and cardiovascular remodeling. Through MR signaling and subsequent genomic events, as well as through nongenomic pathways, ALD exerts effects in non-epithelial cells, such as cardiomyocytes, VSMCs, endothelial cells, mesangial cells and podocytes. Furthermore, MR expression has recently been discovered in non-epithelial tissues, including cardiac tissue and VSMCs. ALD causes inflammation and insulin resistance, which lead to fibrosis and remodeling in the heart, vasculature and kidney $(17,18)$.

In a previous study, we reported that UII is abundantly expressed in the adventitia (4) and that UII stimulated phenotypic conversion, proliferation, collagen synthesis, and production of transforming growth factor- $\beta 1$ and LTC4 in AFs and intracellular signal transduction pathways, including calcineurin, PKC, $\mathrm{Ca}^{2+}$ MAPK, and Rho kinase, may be involved in these processes (4,19-21). However, the role of the vascular adventitia and the mechanisms driving the inflammatory response during the genesis of UII-induced cardiovascular diseases are poorly understood. In the present study, we assessed the effect of UII on ALD and ALD receptor (ALD-R) mRNA expression in AFs and tunica adventitia of rat vessels and elucidated the molecular mechanisms underlying these effects.

\section{Materials and methods}

Animals. Male Sprague-Dawley rats weighing 180-200 g were supplied by the Experimental Animal Center Hubei University of Medicine. This study was carried out in strict accordance with the recommendations in the Guide for the Care and Use of Laboratory Animals of the Hubei University of Medicine. The protocol was approved by the Committee on the Ethics of Animal Experiments of the Hubei University of Medicine. All surgery was performed under sodium pentobarbital anesthesia, and all efforts were made to minimize suffering.

Materials and reagents. Rat UII was acquired from Phoenix Pharmaceuticals Inc. (Belmont, CA, USA). A rat ALD enzyme-linked immunosorbent assay (ELISA) kit was obtained from Sangon Biotech (Shanghai, China). Fetal bovine serum (FBS) was acquired from HyClone (Logan, UT, USA). The ALD antibody from Novus Biologicals (Littleton, CO, USA), the ALD-R antibody from Enzo Life Sciences (Lausen, Switzerland). The calcineurin inhibitor cyclosporin A (CSA), the $\mathrm{Ca}^{2+}$ channel blocker nicardipine and Dulbecco's modified
Eagle's medium/F12 (DMEM/F12) were purchased from Sigma-Aldrich; Merck KGaA (St. Louis, MO, USA). The signal transduction blockers PD98059 (for mitogen-activated protein kinase), Y-27632 (for Rho-associated protein kinase) and H-7 (for protein kinase $\mathrm{C}$ ) were acquired from Calbiochem (Darmstadt, Germany); High Capacity cDNA Reverse Transcription kits and SYBR Select Master Mix were purchased from Applied Biosystems (Foster City, CA, USA); and RIPA lysis buffer and TRIzol reagent were acquired from Invitrogen (Carlsbad, CA, USA). PCR primers were designed and synthesized by Sangon Biotech (Shanghai, China), and their sequences are shown in Table I. All other chemicals and reagents were of analytical grade.

Hematoxylin and eosin $(H \& E)$ staining and immunohistochemistry. Vessels were performed in $10 \%$ formalin-fixed, paraffin-embedded, cut into $10 \mu \mathrm{m}$ serial sections and then mounted on slides. The slides were stained with H\&E for histological examination. For immunohistochemical staining, sections were deparaffinized with xylene and rehydrated by immersion into decreasing concentrations of ethanol. Endogenous peroxidase activity was blocked using 3\% hydrogen peroxide solution for $10 \mathrm{~min}$, followed by citric acid buffer ( $\mathrm{pH}$ 6.0) microwave antigen retrieval. Nonspecific protein binding was blocked by $30 \mathrm{~min}$ incubation in 5\% bovine serum (Wuhan Boster Biological Technology, Ltd., Wuhan, China). Sections were incubated with primary antibodies: Antibodies against aldosterone (1:50), aldosterone receptor $(1: 100)$, overnight at $4^{\circ} \mathrm{C}$, followed by $5 \mathrm{~min}$ wash in PBS for 3 times. Sections were then incubated for $1 \mathrm{~h}$ at RT with HRP-labelled secondary antibodies. DAB (Boster) for 2 min at RT and counterstaining was made using hematoxylin, dehydrated and clarified by a conventional method, and prepared for examination under a light microscope.

Tissue incubation. Rats were anesthetized and rapidly euthanized by decapitation. The full length of the thoraco-abdominal aorta was excised under aseptic conditions and placed into DMEM/F12. The aorta was sectioned longitudinally after the loose connective tissue and collateral vessels were removed. The blunt side of ophthalmic bending forceps was used to removed endothelial cells and medial layer by gently rubbing. Eye scissors were used to cut the remaining tissue, which was predominantly composed of the adventitia, as small as possible. The adventitia fragments were distributed into $1.5 \mathrm{ml}$ Eppendorf tubes after they were weighed ( $100 \mathrm{mg} /$ tube) and incubated on a shaker under different intervention conditions at $37^{\circ} \mathrm{C}$ in a cell incubator (22).

The experimental groups consisted of: i) Control groups, with tissues incubated in serum-free DMEM/F12; ii) the UII groups, in which $10^{-10}$ to $10^{-6} \mathrm{~mol} / \mathrm{l} \mathrm{UII}$ was added to the serum-free medium; and iii) the UII + inhibitor groups, in which tissues were pretreated with different signal transduction blockers (concentration was $10^{-5} \mathrm{~mol} / \mathrm{l}$ ), including Y-27632, H7, PD98059, CSA and nicardipine in serum-free medium for $0.5 \mathrm{~h}$ prior to addition of UII. After $6 \mathrm{~h}$ of UII incubation, the samples were collected.

Cell culture. AFs from the aorta were prepared as described by Kim et al (23) and Tsuruda et al (24) with slight modifications. 
Table I. Forward and reverse primers for the rat ALD receptor and $\beta$-actin.

\begin{tabular}{llcr}
\hline Primer & \multicolumn{1}{c}{ Sequence } & Amplicon size (bp) & Annealing temperature $\left({ }^{\circ} \mathrm{C}\right)$ \\
\hline ALD-R & F: 5'-CGGCAAATCTCAACAACTCAAGG-3' & $240 \mathrm{bp}$ & 58 \\
ALD-R & R: 5'-CCTCTGTCTTAGGGAAAGGAACG-3' & \\
$\beta$-actin & F: 5'-CACGATGGAGGGGCCGGACTCATC-3' & $240 \mathrm{bp}$ & 58 \\
$\beta$-actin & R: 5'-TAAAGACCTCTATGCCAACACAGT-3' & \\
\hline
\end{tabular}

ALD-R, aldosterone receptor; F, forward; R, reverse.

Adventitia tissues mentioned above were placed in a $25 \mathrm{~cm}^{2}$ tissue culture flask containing DMEM/F12 supplemented with 20\% FBS. After 5-8 days, the fibroblasts were harvested with trypsin prior to forming a confluent monolayer and seeded onto new dishes containing DMEM/F12 medium supplemented with $10 \%$ FBS. The growth characteristics and morphology of the cells were typical of fibroblasts and were distinguished from VSMCs by immunohistochemical staining positive for 'Vimentin' and negative for ' $\alpha$-SMA'. AFs used for experiments in this study were at passages two and three.

RNA isolation. Total RNA was isolated directly from AFs using TRIzol reagent according to the manufacturer's instructions (Invitrogen). Then, the RNA was treated with DNase I to remove residual traces of DNA. The RNA concentration was quantified using a spectrophotometer (NanoDrop 2000; Thermo Fischer Scientific, Inc., Waltham, MA, USA) measuring the OD260/280 ratio (1.8-2.0). Agarose gel electrophoresis (2\%) and GoldView nucleic acid staining were used to examine RNA integrity.

$R T-P C R$. Reverse transcription was performed with High Capacity cDNA Reverse Transcription kits (Applied Biosystems), which included buffer, dNTP mix, random primer and reverse transcriptase, according to the manufacturer's instructions. The PCR was conducted on a PCR instrument (Bio-Rad Laboratories, Inc., Hercules, CA, USA), initial denaturing was performed at $95^{\circ} \mathrm{C}$ for $5 \mathrm{~min}$; then, 35 cycles at $95^{\circ} \mathrm{C}$ for $45 \mathrm{sec}$ (denaturing), at $58^{\circ} \mathrm{C}$ for $\mathrm{ALD}-\mathrm{R}$ and $\beta$-actin for $45 \mathrm{sec}$ (annealing), at $72^{\circ} \mathrm{C}$ for $60 \mathrm{sec}$ (extension) and a further extension at $72^{\circ} \mathrm{C}$ for 3 min were carried out. After amplification, the RT-PCR products were electrophoresed on $1 \%$ agarose gel containing with ethidium bromide, viewed by UV light.

Quantitative real-time PCR. ALD-R and $\beta$-actin complementary DNA (cDNA) was synthesized as previously described. For quantitative real-time RT-PCR, gene expression was quantified using SYBR select master mix (Applied Biosystems). The reagent concentrations used were based on the manufacturer's instructions. Primers targeting rat ALD-R and $\beta$-actin are listed in Table I. PCR conditions were $95^{\circ} \mathrm{C}$ for $10 \mathrm{~min}$, followed by 40 cycles of $94^{\circ} \mathrm{C}$ for $15 \mathrm{sec}, 60^{\circ} \mathrm{C}$ for $1 \mathrm{~min}$. The relative mRNA levels of ALD-R in AFs were determined using the comparative threshold cycle (CT) method using the $2^{-\Delta \Delta \mathrm{CT}}$ equation with $\beta$-actin as an internal control. Each experimental condition was conducted in triplicate.

ELISA. The ELISA was performed with a rat ALD ELISA kit to assess the release of ALD into the culture medium. Briefly, after treatment with the respective stimuli, the culture medium was collected and then centrifuged to obtain the supernatant. The ELISA was conducted according to the manufacturer's directions. The absorbance was read at $450 \mathrm{~nm}$ by a microplate reader.

Statistical analysis. Data are expressed as mean \pm SEM. Statistical differences among multiple groups were analyzed by one-way analysis of variance (ANOVA) followed by Dunnett's test for multiple comparisons, and a Student t-test was used for the statistical analysis of differences between two groups. All data were analyzed with the statistical software GraphPad Prism 5.0 software (GraphPad Software, San Diego, CA, USA). P-values $<0.05$ were considered to indicate a statistically significant difference.

\section{Results}

ALD and its receptors were expressed on adventitia. $\mathrm{H} \& \mathrm{E}$ staining was used to observe the morphology of the blood vessels, and Immunohistochemistry was used to confirm whether aldosterone and its receptors were expressed on adventitia. As shown in Fig. 1, both ALD and its receptors were expressed on tunica adventitia of vessels.

Effect of UII on ALD synthesis in AFs. To determine the role of UII in the synthesis of vasoactive substances in AFs and the signaling pathways associated with this process, we tested the effects of UII on ALD secretion, which is an important indicator of vascular remodeling. After UII stimulation, AFs underwent the phenotypic transformation from fibroblasts to myofibroblasts, demonstrating proliferation, migration, intense ALD secretion and $\alpha$-SMA expression.

As shown in Fig. 2, the ELISA results indicated that ALD secretion increased after $4 \mathrm{~h}$ of UII $\left(10^{-8} \mathrm{~mol} / \mathrm{l}\right)$ stimulation $(\mathrm{P}<0.05)$ and reached a maximum at $24 \mathrm{~h}(\mathrm{P}<0.01)$ (Fig. 2). UII also upregulated ALD secretion in a concentration-dependent manner (Fig. 3). Maximal effectiveness was achieved at $10^{-8} \mathrm{~mol} / \mathrm{l}(\mathrm{P}<0.01)$, as ALD secretion increased by $20.1 \%\left(10^{-10} \mathrm{~mol} / \mathrm{l}, \mathrm{P}<0.05\right), 54.7 \%\left(10^{-9} \mathrm{~mol} / 1, \mathrm{P}<0.05\right)$, 99.2\% (10 $\left.0^{-8} \mathrm{~mol} / \mathrm{l}, \mathrm{P}<0.01\right), 91 \%\left(10^{-7} \mathrm{~mol} / \mathrm{l}, \mathrm{P}<0.01\right)$ and $35.7 \%\left(10^{-6} \mathrm{~mol} / \mathrm{l} ; \mathrm{P}<0.01\right)$. 

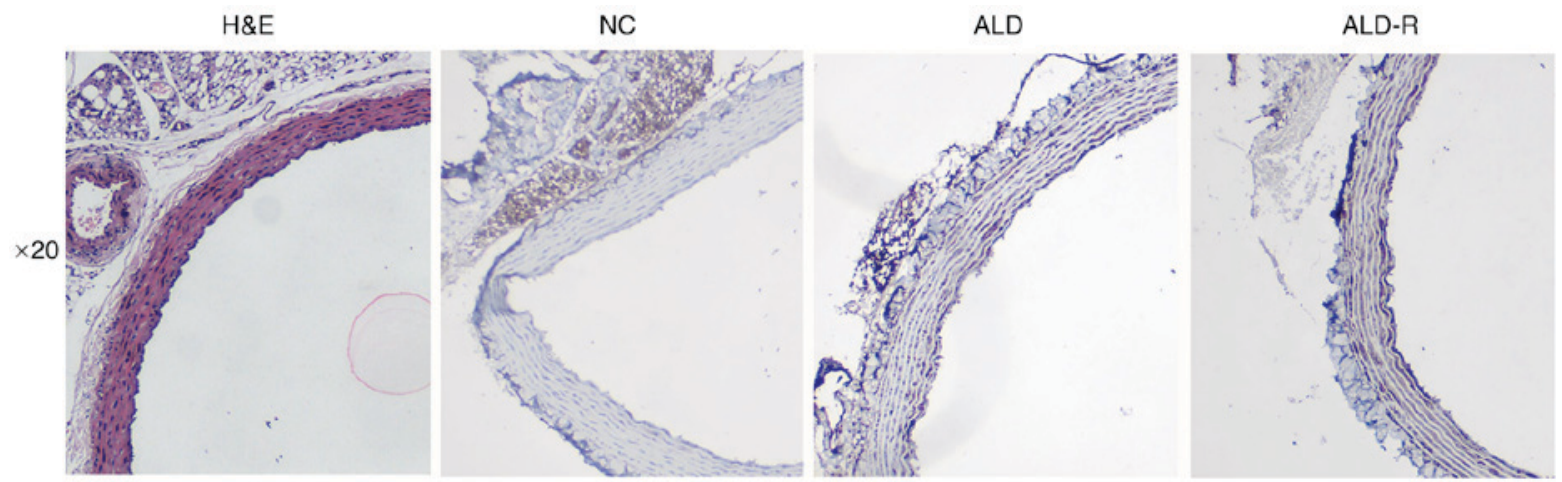

Figure 1. Expression of ALD and its receptors in tunica adventitia of vessels. The morphology of the blood vessels was shown in H\&E staining, for the immunohistochemical analysis, brown staining indicates areas with positive expression, compared with NC both ALD and its receptors were expressed on tunica adventitia of vessels. H\&E, hematoxylin and eosin; NC, negative control; ALD, aldosterone; ALD-R, aldosterone receptor.

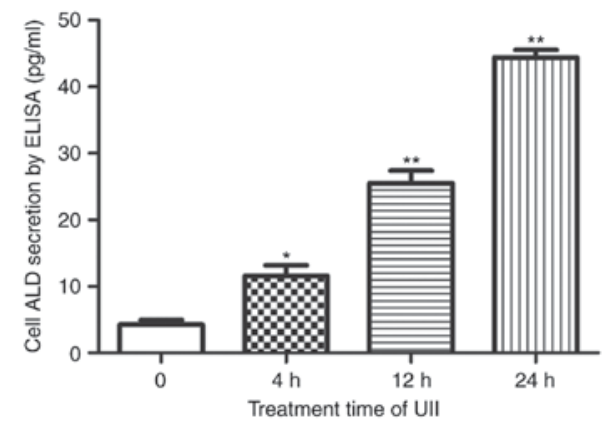

Figure 2. Time course of UII treatment on ALD secretion from AFs ( $\mathrm{n}=5)$. After rat AFs were stimulated with UII $\left(10^{-8} \mathrm{~mol} / \mathrm{l}\right)$ for the indicated times, culture medium was collected, and ALD levels were tested by ELISA using a $450 \mathrm{~nm}$ wavelength for OD measurements. A time-dependent effect of UII on ALD expression was observed. First bar, 0 h/untreated cells; second through fourth bars, cells treated with UII ( 4 to $24 \mathrm{~h}$ ). The data are presented as the mean \pm SEM. ${ }^{*} \mathrm{P}<0.05$ vs. control; ${ }^{* * *} \mathrm{P}<0.01$ vs. control. AFs, adventitial fibroblasts; UII, urotensin II; ALD, aldosterone.

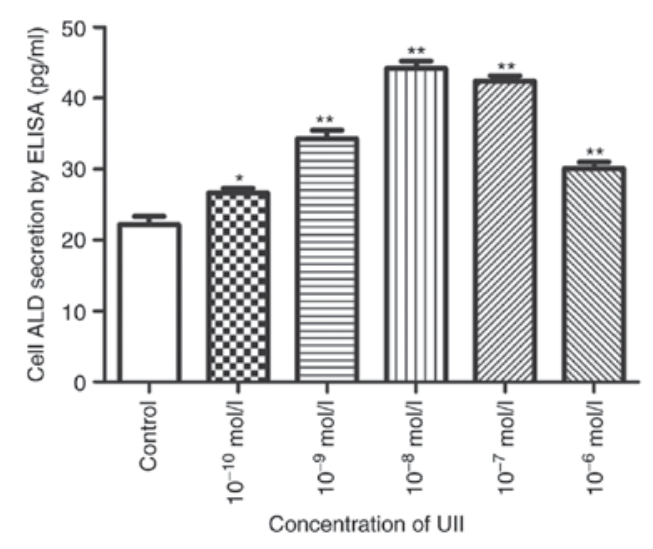

Figure 3. In vitro effect of different concentrations of UII on ALD secretion in cultured AFs ( $\mathrm{n}=5)$. After rat AFs were stimulated with UII $\left(10^{-10}\right.$ to $\left.10^{-6} \mathrm{~mol} / \mathrm{l}\right)$ for $24 \mathrm{~h}$, culture medium was collected, and ALD levels were determined by ELISA using a $450 \mathrm{~nm}$ wavelength for OD measurements. A concentration-dependent effect of UII on ALD expression was observed. First bar, untreated control cells; second through sixth bars, cells stimulated with UII $\left(10^{-10}\right.$ to $\left.10^{-6} \mathrm{~mol} / \mathrm{l}\right)$. The results are shown as the mean \pm SEM. ${ }^{*} \mathrm{P}<0.05$ vs. control; ${ }^{* *} \mathrm{P}<0.01$ vs. control. AFs, adventitial fibroblasts; UII, urotensin II; ALD, aldosterone.

After treatment with UII and different inhibitors (Fig. 4), including PD98059, Y-27632, H7, CSA and

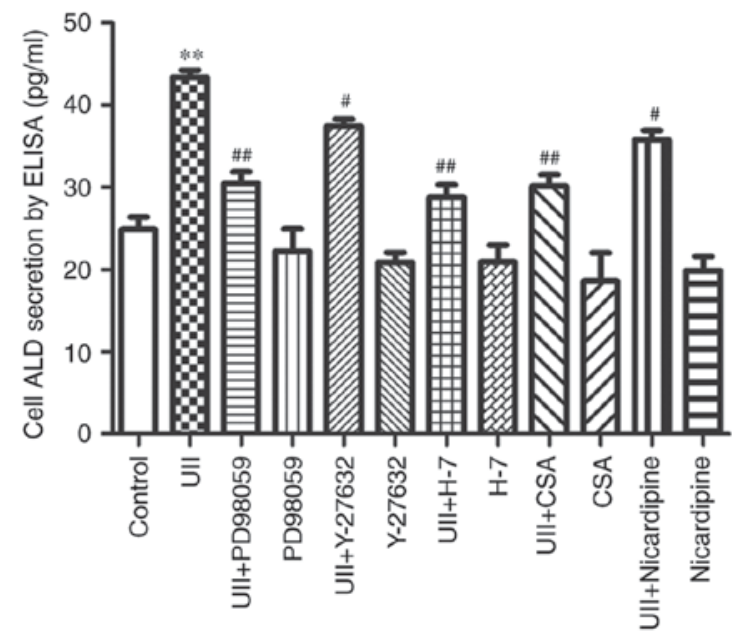

Figure 4. Effects of different signal transduction blockers on UII-induced ALD secretion from AFs $(\mathrm{n}=3)$. Rat AFs were preincubated with PD98059 $\left(10^{-5} \mathrm{~mol} / \mathrm{l}\right), \mathrm{Y}-27632\left(10^{-5} \mathrm{~mol} / \mathrm{l}\right), \mathrm{H}-7\left(10^{-5} \mathrm{~mol} / \mathrm{l}\right), \mathrm{CSA}\left(10^{-5} \mathrm{~mol} / \mathrm{l}\right)$ or nicardipine $\left(10^{-5} \mathrm{~mol} / \mathrm{l}\right)$ for $30 \mathrm{~min}$ before the addition of UII $\left(10^{-8} \mathrm{M}\right)$ for $24 \mathrm{~h}$ or treated with inhibitors alone for $24 \mathrm{~h}$. The figure shows ALD secretion. The data are presented as the mean \pm SEM. ${ }^{* *} \mathrm{P}<0.01$ vs. control; ${ }^{*} \mathrm{P}<0.05$ vs. UII alone; ${ }^{\# \#} \mathrm{P}<0.01$ vs. UII alone. AFs, adventitial fibroblasts; UII, urotensin II; ALD, aldosterone.

nicardipine, the ELISA results (Fig. 3) showed that ALD secretion was inhibited to varying degrees under all conditions, suggesting that MAPK, Rho, PKC, calcineurin and $\mathrm{Ca}^{2+}$ signaling, respectively, may be involved in UII-induced ALD synthesis.

Effect of UII on ALD-R mRNA expression in AFs. UII induced dose- and time-dependent increases in ALD expression, with the maximal effect observed at a dose of $10^{-8} \mathrm{~mol} / \mathrm{l}$ for $24 \mathrm{~h}(\mathrm{P}<0.01$, Figs. 2 and 3$)$. We used this fixed condition to investigate the effect of UII on ALD-R expression in AFs. As shown in Fig. 5 RT-PCR results indicated that ALD-R expression increased after $24 \mathrm{~h}$ of UII stimulation compared with that of the control group without UII stimulation $(\mathrm{P}<0.01)$. Furthermore, this UII-induced effect was attenuated following pretreatment with kinase inhibitors, including PD98059, Y-27632, H7, CSA or nicardipine, suggesting that MAPK, Rho, PKC, calcineurin and $\mathrm{Ca}^{2+}$ signaling, 


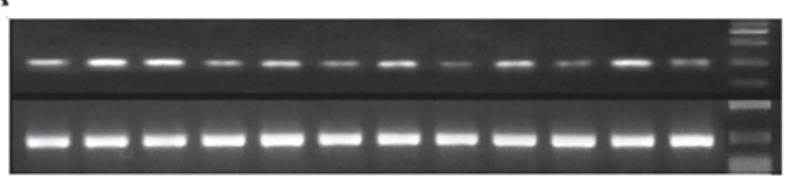

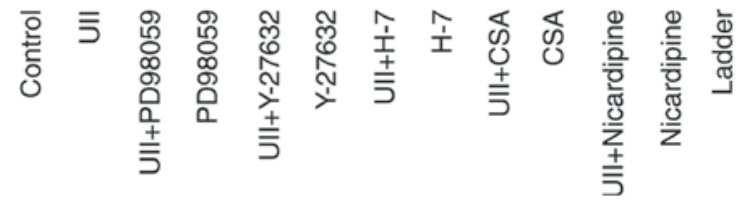

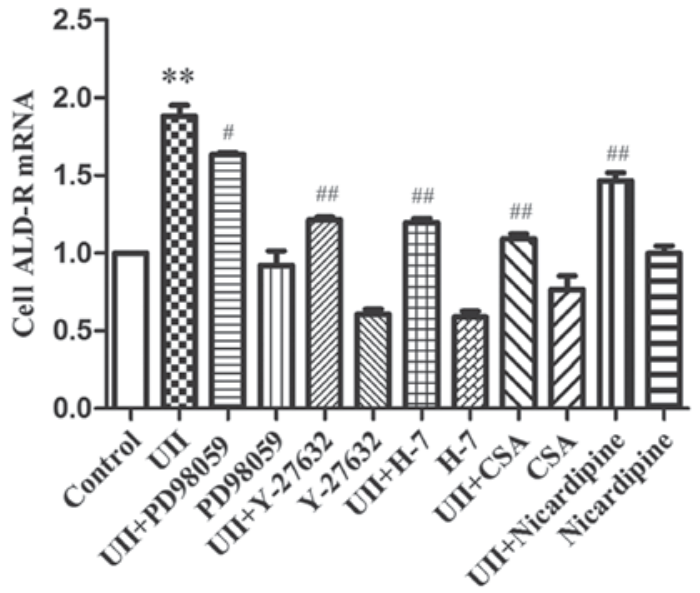

Figure 5. Effects of different signal transduction blockers on ALD-R expression in AFs induced by UII. Rat AFs were preincubated with PD98059 $\left(10^{-5} \mathrm{~mol} / \mathrm{l}\right), \mathrm{Y}-27632\left(10^{-5} \mathrm{~mol} / \mathrm{l}\right), \mathrm{H}-7\left(10^{-5} \mathrm{~mol} / \mathrm{l}\right), \mathrm{CSA}\left(10^{-5} \mathrm{~mol} / \mathrm{l}\right)$ or nicardipine $\left(10^{-5} \mathrm{~mol} / \mathrm{l}\right)$ for $30 \mathrm{~min}$ followed by UII $\left(10^{-8} \mathrm{~mol} / \mathrm{l}\right)$ treatment for $24 \mathrm{~h}$ or inhibitors were administered alone for $24 \mathrm{~h}$. (A) Representative PCR results for ALD-R expression. $\beta$-actin was used to verify equal loading of cellular cDNA. (B) Quantitative results of the real-time PCR. ${ }^{* *} \mathrm{P}<0.01$ vs. control; ${ }^{\#} \mathrm{P}<0.05$ vs. UII alone; ${ }^{\# \#} \mathrm{P}<0.01$ vs. UII alone. AFs, adventitial fibroblasts; UII, urotensin II; ALD-R, aldosterone receptor.

respectively, may be involved in UII-induced ALD-R expression (Fig. 5).

Effect of UII on ALD synthesis and ALD-R expression in adventitia. We used the above-described fixed UII treatment conditions to examined the effect of UII on the expression and secretion of ALD and ALD-R in the adventitia and on the synthesis of vasoactive substances in the adventitia, as well as on the signaling pathways associated with these processes. After UII treatment, the adventitia showed intense ALD and ALD-R secretion.

After cotreatment with UII and the various inhibitors for $6 \mathrm{~h}$, the ELISA results showed that ALD secretion was inhibited to varying degrees (Fig. 6), suggesting that MAPK, Rho, $\mathrm{PKC}$, calcineurin and $\mathrm{Ca}^{2+}$ signaling may be involved in UII-induced ALD and ALD-R expression.

\section{Discussion}

ALD is an important hormone in the renin-angiotensin-ALD system (RAAS) and acts in the distal renal tubule. Angiotensin II and potassium primarily stimulate ALD release. ALD binds to the MR and, in conjunction with various transcription factors, induces the production of proteins involved in sodium reabsorption and potassium excretion. The serum
A

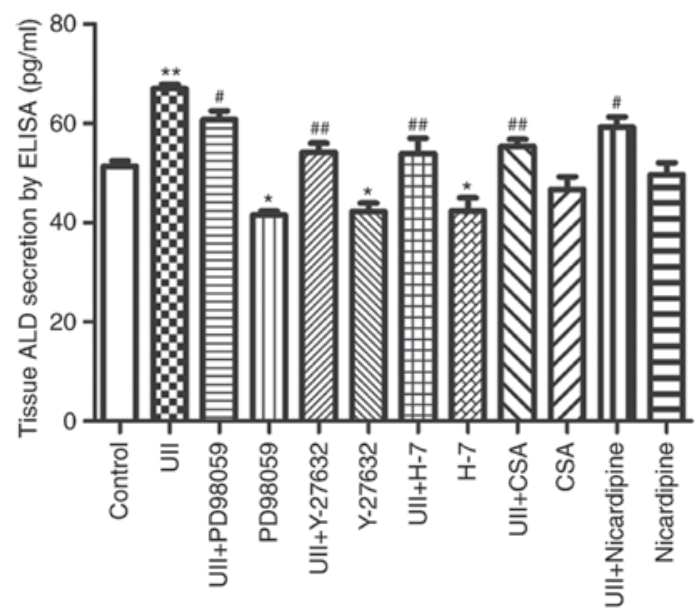

B

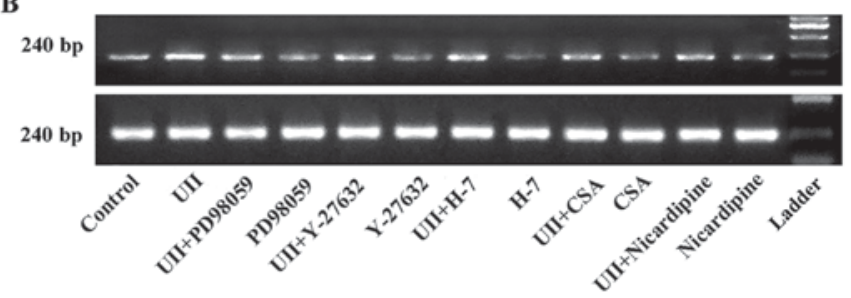

C

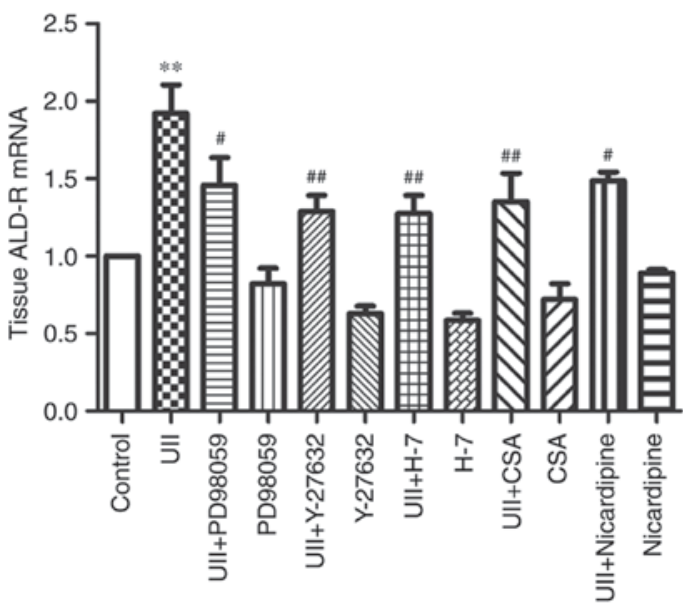

Figure 6. Effects of different signal transduction blockers on UII-induced ALD and ALD-R expression in adventitial tissue. The adventitia tissue was rapidly sectioned into small pieces and distributed into $1.5 \mathrm{ml}$ Eppendorf tubes after weighing ( $100 \mathrm{mg} /$ tube). The tissues were incubated on a shaker at $37^{\circ} \mathrm{C}$ in a humidified atmosphere of $95 \%$ (volume fraction) $\mathrm{O}_{2}-5 \%$ (volume fraction) $\mathrm{CO}_{2}$ and subjected to different intervention conditions. The tissues were either preincubated with PD98059 (10 $\left.0^{-5} \mathrm{~mol} / \mathrm{l}\right), \mathrm{Y}-27632\left(10^{-5} \mathrm{~mol} / \mathrm{l}\right), \mathrm{H}-7$ $\left(10^{-5} \mathrm{~mol} / \mathrm{l}\right), \mathrm{CSA}\left(10^{-5} \mathrm{~mol} / \mathrm{l}\right)$ or nicardipine $\left(10^{-5} \mathrm{~mol} / \mathrm{l}\right)$ for $30 \mathrm{~min}$ followed by treatment with UII $\left(10^{-8} \mathrm{~mol} / \mathrm{l}\right)$ for $6 \mathrm{~h}$, or the inhibitors were added alone for $6 \mathrm{~h}$. (A) ALD secretion. (B) A representative PCR of ALD-R expression, and $\beta$-actin was used to verify equal loading of cellular cDNA. (C) The quantitative PCR results. ${ }^{*} \mathrm{P}<0.05$ vs. control; ${ }^{* *} \mathrm{P}<0.01$ vs. control; ${ }^{\#} \mathrm{P}<0.05$ vs. UII alone; ${ }^{\# \#} \mathrm{P}<0.01$ vs. UII alone. AFs, adventitial fibroblasts; UII, urotensin II; ALD-R, aldosterone receptor.

levels of ALD the levels of glucocorticoids are particularly important in this process.

Increasing evidence has shown that ALD plays a pivotal role in the vascular inflammatory response by increasing the expression of adhesion molecules, cytokines and chemokines as well as growth factors. These molecules in turn promote 


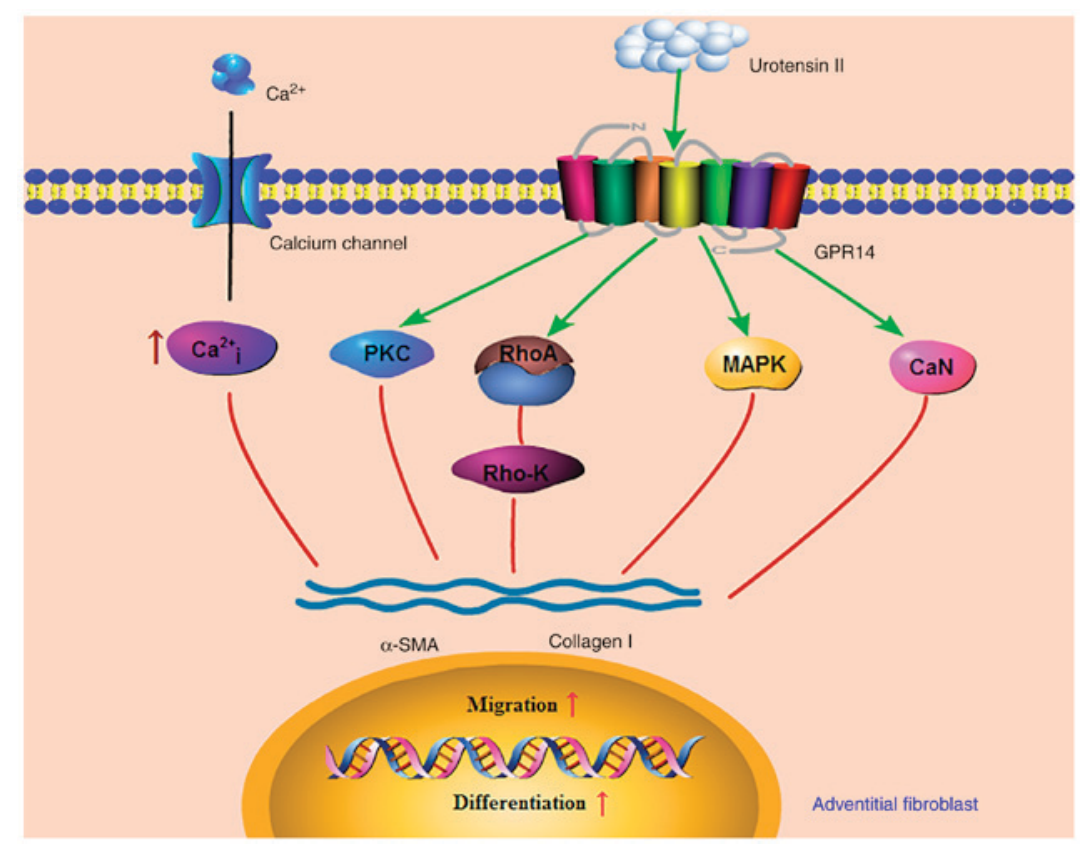

Figure 7. Mechanism of UII promoting phenotypic transformation of AFs. UII may stimulate AFs phenotypic conversion, migration, and collagen I synthesis via the PKC, MAPK, calcineurin, Rho kinase and $\mathrm{Ca}^{2+}$ signal transduction pathways, contributing to the development of vascular remodeling through $\mathrm{AFs}$ activation. UII, urotensin II; PKC, protein kinase C; CSA, cyclosporine A; MAPK, mitogen-activated protein kinase; CaN, calcineurin; Rho-K, Rho protein kinase; $\alpha$-SMA, $\alpha$-smooth muscle actin.

the recruitment and adhesion of inflammatory cells, inducing the initiation and progression of many cardiovascular diseases, including hypertension, atherosclerosis and restenosis. Blockade of the RAAS is the most effective strategy to prevent renal disease progression, heart failure, and cardiovascular death. ALD administration causes perivascular inflammation and fibrosis, and an MR antagonist reduced atherosclerotic lesions in different models of atherosclerosis, supporting this strategy (25-27). Additionally, this reduction in atherosclerosis progression was accompanied by a reduction in inflammatory markers $(26,27)$. Some of these beneficial effects can be attributed to either ALD reduction or MR antagonism, both of which provide advantages beyond controlling hypertension, such as improvements in glucose metabolism, fibrosis, and inflammation. Effector molecules whose downstream activities can be affected by ALD include angiotensin II, endothelin, growth factors, plasminogen activator inhibitor-1 (PAI-1), and oxidative stress (28). MR is also expressed in VSMCs and endothelium in the vasculature and contributes to vascular function and remodeling (29).

The major pathogenesis of cardiovascular disease is vascular inflammation, which is observed throughout the whole process of initiation, progression and complications of cardiovascular disease. Atherosclerosis is a cardiovascular disease characterized by a chronic low-grade inflammatory process (30). Numerous studies have demonstrated that ALD disorder is associated with a proinflammatory vascular response. Rocha et al found that in coronary arteries, a short-term infusion of ALD in uninephrectomized rats fed a high-salt diet elicited infiltration of inflammatory cells in these arteries, which was associated with necrotic lesions and ischemia of the adjacent myocardium. This cell infiltration was preceded by an increase in proinflammatory mediators, such as MCP-1, ICAM-1, COX-2 and cytokines (31,32).
Vascular remodeling is critical in cardiovascular physiology and has the greatest potential for useful translation from basic research to clinical applications. The adventitia plays a key role in vascular remodeling, as recent studies have demonstrated that the adventitia is the initiation site for this remodeling. Following injury and stimulation, AFs are activated and differentiate into myofibroblasts, which show contractile properties as well as significant proliferative and synthetic activities. These myofibroblasts migrate to the intima and contribute to neointima formation. AF proliferation, migration, differentiation and collagen synthesis are involved in vascular remodeling (19); however, the mechanisms underlying vascular remodeling in the adventitia are still poorly understood.

A limited number of studies have examined the effects of UII on ALD expression in AFs and its role in vascular remodeling. Although ALD was shown to be critical in inducing vascular remodeling in vivo, the role of ALD in UII-induced vascular remodeling remains unclear, and little is known about whether AFs are a novel source of ALD. As vascular remodeling is a complex process in vivo, we performed an in vitro experiment to elucidate the role of ALD in UII-induced vascular remodeling.

Previously, little was known regarding ALD expression in AFs. In the present study, we showed for the first time that both ALD and its receptors were expressed on tunica adventitia of vessels, and UII promotes ALD secretion and mRNA expression of its receptor in AFs in a time- and dose-dependent manner, suggesting that UII may stimulate ALD expression.

In the past, we have confirmed that UII induces AFs phenotypic transformation (Fig. 7) and Secretion of inflammatory factors via the UT receptor followed by various intracellular signal transduction mechanisms, such as Gq protein, protein tyrosine kinases of ERK and PKC, and the RhoA/ROCK-related 
pathways $(19,21)$. In the present study, we found that the effects of UII upregulared ALD expression could be blocked by inhibitors targeting Rho kinase, PKC, MAPK, calcineurin, and $\mathrm{Ca}^{2+}$ channels. Therefore, activation of these signaling pathways may be involved in UII-induced ALD expression.

We previously showed that UII can activate AFs in an autocrine/paracrine manner $(4,20)$. Others researchers have demonstrated that UII stimulates monocyte chemotaxis (33); promotes foam cell formation in human monocyte-derived macrophages (5); induces inflammatory activation of endothelial cells by promoting expression of the proinflammatory cytokines IL-1 $\beta$ and IL-6, the adhesion molecule VCAM-1, and tissue factors in endothelial cells; and promotes the adhesion of monocytes to endothelial cells (9). Here, we found that UII may directly induce ALD expression in AFs, possibly in an autocrine/paracrine manner. ALD may mediate the effects of UII in adventitial inflammatory activation, which is a new mechanism through which UII accelerates vascular remodeling, such as that observed in atherosclerosis.

In conclusion, the results of this study indicated for the first time that UII can stimulate the secretion of ALD in cultured AFs in a time- and dose-dependent manner. In addition, UII-induced secretion of ALD was significantly blocked by the MAPK kinase inhibitor PD98059, the Rho protein kinase inhibitor Y-27632, the PKC inhibitor $\mathrm{H}-7$, the calcineurin inhibitor CSA and the $\mathrm{Ca}^{2+}$ channel blocker nicardipine. These findings elucidate the mechanisms responsible for the progression of cardiovascular disease, such as atherosclerosis, vascular restenosis, and hypertension associated with UII. Moreover, these results may contribute to broaden our understanding of the novel effects of UII and may provide new insights into the mechanism underlying adventitial inflammation. Finally, inhibiting these pathways may be a novel therapeutic approach for the treatment of vascular inflammation in cardiovascular disease.

\section{Acknowledgements}

This study was supported by grants from the Natural Science Foundation of Hubei Province (no. 2011CDC049) and the Taihe Hospital Foster Fund for the National Natural Science Foundation of China (no. 2014PY03). The experiments were further supported by the Institute of Basic Medical Research, Hubei University of Medicine, Clinical Laboratory of Shiyan Taihe Hospital and Institute of Life Sciences of Shiyan Taihe Hospital. We are grateful to Ms. Han-Qin Wang (Institute of Basic Medical Research, Hubei University of Medicine), Mr. Zong-Tao Yu and Ji-Cai Zhang (Clinical Laboratory of Shiyan TaiHe Hospital) for their helpful suggestions.

\section{References}

1. Ames RS, Sarau HM, Chambers JK, Willette RN, Aiyar NV, Romanic AM, Louden CS, Foley JJ, Sauermelch CF, Coatney RW, et al: Human urotensin-II is a potent vasoconstrictor and agonist for the orphan receptor GPR14. Nature 401: 282-286, 1999 .

2. Ross B, McKendy K and Giaid A: Role of urotensin II in health and disease. Am J Physiol Regul Integr Comp Physiol 298: R1156-R1172, 2010.

3. Iglewski $M$ and Grant SR: Urotensin II-induced signaling involved in proliferation of vascular smooth muscle cells. Vasc Health Risk Manag 6: 723-734, 2010.
4. Zhang Y, Li Y, Wei R, Wang Z, Bu D, Zhao J, Pang Y and Tang C: Urotensin II is an autocrine/paracrine growth factor for aortic adventitia of rat. Regul Pept 151: 88-94, 2008.

5. Watanabe T, Suguro T, Kanome T, Sakamoto Y, Kodate S, Hagiwara T, Hongo S, Hirano T, Adachi M and Miyazaki A: Human urotensin II accelerates foam cell formation in human monocyte-derived macrophages. Hypertension 46: 738-744, 2005.

6. Tsoukas P, Kane E and Giaid A: Potential clinical implications of the urotensin II receptor antagonists. Front Pharmacol 2: 38, 2011.

7. Watson AM, Olukman M, Koulis C, Tu Y, Samijono D, Yuen D, Lee C, Behm DJ, Cooper ME, Jandeleit-Dahm KA, et al: Urotensin II receptor antagonism confers vasoprotective effects in diabetes associated atherosclerosis: Studies in humans and in a mouse model of diabetes. Diabetologia 56: 1155-1165, 2013

8. Hassan GS, Douglas SA, Ohlstein EH and Giaid A: Expression of urotensin-II in human coronary atherosclerosis. Peptides 26: 2464-2472, 2005.

9. Park SL, Lee BK, Kim YA, Lee BH and Jung YS: Inhibitory effect of an urotensin II receptor antagonist on proinflammatory activation induced by urotensin II in human vascular endothelial cells. Biomol Ther (Seoul) 21: 277-283, 2013.

10. Enzerink A and Vaheri A: Fibroblast activation in vascular inflammation. J Thromb Haemost 9: 619-626, 2011.

11. Li AC and Glass CK: The macrophage foam cell as a target for therapeutic intervention. Nat Med 8: 1235-1242, 2002.

12. Maiellaro $\mathrm{K}$ and Taylor WR: The role of the adventitia in vascular inflammation. Cardiovasc Res 75: 640-648, 2007.

13. Jiang W, Yang JH, Pan CS, Qi YF, Pang YZ and Tang CS: Effects of adrenomedullin on cell proliferation in rat adventitia induced by aldosterone. J Hypertens 22: 1953-1961, 2004.

14. Xu F, Ji J, Li L, Chen R and Hu W: Activation of adventitial fibroblasts contributes to the early development of atherosclerosis: A novel hypothesis that complements the 'Response-to-Injury Hypothesis' and the 'Inflammation Hypothesis'. Med Hypotheses 69: 908-912, 2007.

15. Stenmark KR, Davie N, Frid M, Gerasimovskaya E and Das M: Role of the adventitia in pulmonary vascular remodeling. Physiology (Bethesda) 21: 134-145, 2006.

16. Sartore S, Chiavegato A, Faggin E, Franch R, Puato M, Ausoni S and Pauletto P: Contribution of adventitial fibroblasts to neointima formation and vascular remodeling: From innocent bystander to active participant. Circ Res 89: 1111-1121, 2001.

17. Gilbert $\mathrm{KC}$ and Brown NJ: Aldosterone and inflammation. Curr Opin Endocrinol Diabetes Obes 17: 199-204, 2010.

18. Xanthakis V and Vasan RS: Aldosterone and the risk of hypertension. Curr Hypertens Rep 15: 102-107, 2013.

19. Zhang YG, Li J, Li YG and Wei RH: Urotensin II induces phenotypic differentiation, migration, and collagen synthesis of adventitial fibroblasts from rat aorta. J Hypertens 26: 1119-1126, 2008.

20. Zhang YG, Hu YC, Mao YY, Wei RH, Bao SL, Wu LB and Kuang ZJ: Transforming growth factor- $\beta 1$ involved in urotensin II-induced phenotypic differentiation of adventitial fibroblasts from rat aorta. Chin Med J (Engl) 123: 3634-3639, 2010.

21. Dong X, Ye X, Song N, Zhao J, Di B, Peng F, Tang C and Ding W: Urotensin II promotes the production of LTC4 in rat aortic adventitial fibroblasts through NF- $\mathrm{BB}-5-\mathrm{LO}$ pathway by p38 MAPK and ERK activations. Heart Vessels 28: 514-523, 2013.

22. Kelm M: Nitric oxide metabolism and breakdown. Biochim Biophys Acta 1411: 273-289, 1999.

23. Kim DK, Huh JE, Lee SH, Hong KP, Park JE, Seo JD and Lee WR: Angiotensin II stimulates proliferation of adventitial fibroblasts cultured from rat aortic explants. J Korean Med Sci 14: 487-496, 1999.

24. Tsuruda T, Kato J, Cao YN, Hatakeyama K, Masuyama H, Imamura T, Kitamura K, Asada Y and Eto T: Adrenomedullin induces matrix metalloproteinase-2 activity in rat aortic adventitial fibroblasts. Biochem Biophys Res Commun 325: 80-84, 2004.

25. Rajagopalan S, Duquaine D, King S, Pitt B and Patel P: Mineralocorticoid receptor antagonism in experimental atherosclerosis. Circulation 105: 2212-2216, 2002.

26. Takai S, Jin D, Muramatsu M, Kirimura K, Sakonjo H and Miyazaki M: Eplerenone inhibits atherosclerosis in nonhuman primates. Hypertension 46: 1135-1139, 2005. 
27. Suzuki J, Iwai M, Mogi M, Oshita A, Yoshii T, Higaki J and Horiuchi M: Eplerenone with valsartan effectively reduces atherosclerotic lesion by attenuation of oxidative stress and inflammation. Arterioscler Thromb Vasc Biol 26: 917-921, 2006.

28. Epstein M: Aldosterone and the hypertensive kidney: Its emerging role as a mediator of progressive renal dysfunction: A paradigm shift. J Hypertens 19: 829-842, 2001

29. Ehrhart-Bornstein M, Lamounier-Zepter V, Schraven A, Langenbach J, Willenberg HS, Barthel A, Hauner $\mathrm{H}$, McCann SM, Scherbaum WA and Bornstein SR: Human adipocytes secrete mineralocorticoid-releasing factors. Proc Natl Acad Sci USA 100: 14211-14216, 2003.

30. Libby P, Ridker PM and Maseri A: Inflammation and atherosclerosis. Circulation 105: 1135-1143, 2002.
31. Joffe HV and Adler GK: Effect of aldosterone and mineralocorticoid receptor blockade on vascular inflammation. Heart Fail Rev 10: 31-37, 2005

32. Rocha R, Martin-Berger CL, Yang P, Scherrer R, Delyani J and McMahon E: Selective aldosterone blockade prevents angiotensin II/salt-induced vascular inflammation in the rat heart. Endocrinology 143: 4828-4836, 2002.

33. Segain JP, Rolli-Derkinderen M, Gervois $\mathrm{N}$ Raingeard de la Blétière D, Loirand G and Pacaud P: Urotensin II is a new chemotactic factor for UT receptor-expressing monocytes. J Immunol 179: 901-909, 2007.

(i) (9) This work is licensed under a Creative Commons Attribution-NonCommercial-NoDerivatives 4.0 International (CC BY-NC-ND 4.0) License. 